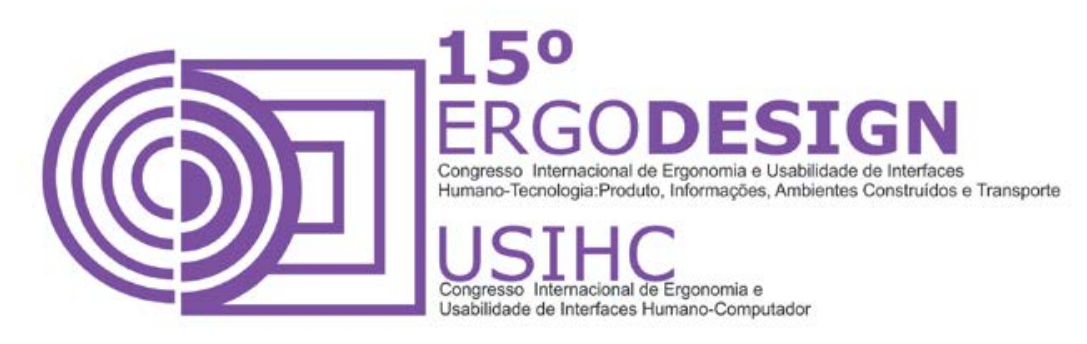

\title{
COMPREENDENDO A PERCEPÇÃO DO USUÁRIO AO VISUALIZAR O EXTINTOR DE INCÊNDIO
}

\author{
RODRIGUES, Yago W. (1); \\ TEIXEIRA, Edson S. Maciel (2); \\ WEISS, Daila Campigotto (3); \\ ALBACH, Dulce de Meira (4); \\ OKIMOTO, Maria Lucia R. (5);
}

$(1,2,3,4,5)$ Programa de Pós-graduação em Design UFPR

(1) E-mail: yagowr5@gmail.com ;

(2) E-mail: edson.teixeira@ifsc.edu.br ;

(3) E-mail: dulce.albach@ufpr.br ;

(4) E-mail: dalisweiss@hotmail.com;

(5) E-mail: lucia.demec@ufpr.br

\begin{abstract}
RESUMO
Situações de emergência podem acontecer a qualquer momento. É necessário que as pessoas que venham a atuar nestas condições tomem decisões a partir de suas percepções sobre o ambiente. Um equipamento de emergência como um extintor de incêndio precisa ter seus pontos mais importantes identificados claramente e rapidamente (uso intuitivo). Sendo assim, este trabalho apresenta um estudo de percepção de um extintor de incêndio com o uso do rastreamento ocular (eye tracking). A metodologia utilizada foi um estudo de caso com doze participantes, os quais tiveram seus movimentos oculares rastreados em dois momentos (situação A e B).
\end{abstract}

\begin{abstract}
Emergency situations can happen at any time. It is necessary for people who may act under these conditions make decisions based on their perceptions of the environment. An emergency equipment such as a fire extinguisher must have its most important points identified clearly and quickly (intuitive use). Thus, this work presents a study of perception of a fire extinguisher with the use of Eye Tracking. The methodology used was a case study with twelve participants, who had their eye movements tracked in two different moments (situation $A$ and $B$ ).
\end{abstract}




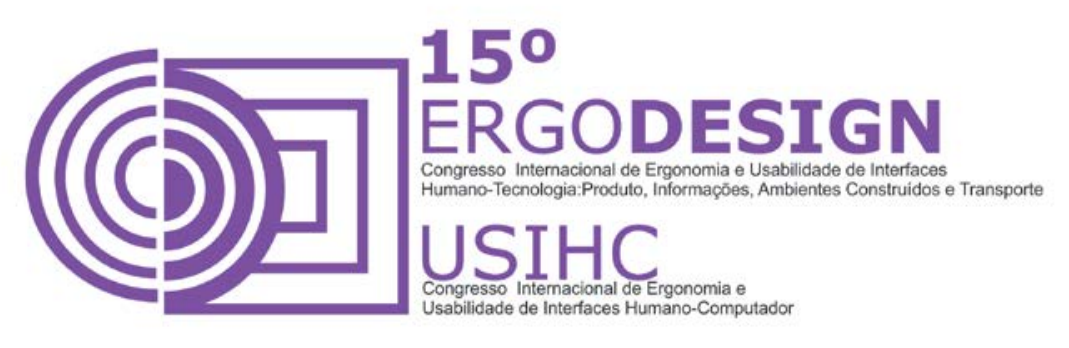

\section{INTRODUÇÃO}

A segurança em ambientes é uma preocupação cada vez maior, principalmente em locais de aglomeração de pessoas e condomínios residenciais. Para isso que existem normas que regram as condições estruturais e ambientais, assim como o dimensionamento dos equipamentos necessários à segurança. Neste contexto, condições de incêndio tomam relevância por estarem diretamente relacionadas à manutenção da vida. E o extintor de incêndio torna-se um equipamento importante. Assim, no âmbito da análise do uso do extintor de incêndio em ambiente doméstico, identifica-se a importância das normas de segurança estabelecidas pelo Corpo de Bombeiros da Polícia Militar do Estado do Paraná (BRASIL, 2014). Este órgão define que emergência "é a situação crítica e fortuita que representa perigo à vida, ao meio ambiente e ao patrimônio, decorrente de atividade humana ou fenômeno da natureza que obriga a uma rápida intervenção operacional".

Considerando que as edificações são de responsabilidade dos proprietários ou dos responsáveis pelo uso, cabe a estes tomarem providências cabíveis para a adequação ao Código de Segurança e às normas vigentes. Desta forma, o CBMPR - Comando do Corpo de Bombeiros Militar (BRASIL, 2011), preconiza o denominado CSCIP - Código de Segurança Contra Incêndio e Pânico, em atendimento ao previsto no artigo $144 \S 5^{\circ}$ da Constituição Federal, ao artigo 48 da Constituição Estadual e ao disposto na Lei Estadual do Paraná $\mathrm{n}^{\circ}$ 16.575 de 28 de setembro de 2010. Os principais objetivos deste Código são o de proteger a vida dos ocupantes das edificações e áreas de risco, em caso de incêndio; dificultar a propagação do incêndio, reduzindo danos ao meio ambiente e ao patrimônio; proporcionar meios de controle e extinção do incêndio; dar condições de acesso para as operações do Corpo de Bombeiros; e proporcionar a continuidade dos serviços nas edificações e áreas de risco.

Há de se considerar que além das leis destacadas, existe uma série de normas que dão base para que os ambientes residenciais estejam preparados para qualquer situação de incêndio emergencial. Entretanto, o cumprimento legal e a disponibilização de extintores de incêndio pode não ser suficiente para que o seu uso seja adequado. Sendo o extintor de incêndio um equipamento de uso eventual e somente em condições de emergência, este pode não ser corretamente interpretado pelo possível usuário. Se o usuário não tiver uma capacitação ou instrução prévia, pode não conseguir tomar a decisão adequada num caso de incêndio. Assim, a percepção de um equipamento de segurança de uso eventual como um extintor de incêndio ganha relevância. Torna-se necessário que o usuário não somente entenda a sua condição de uso, como também tome uma decisão rápida (uso intuitivo), em poucos segundos, já que se encontra em situação de emergência. 


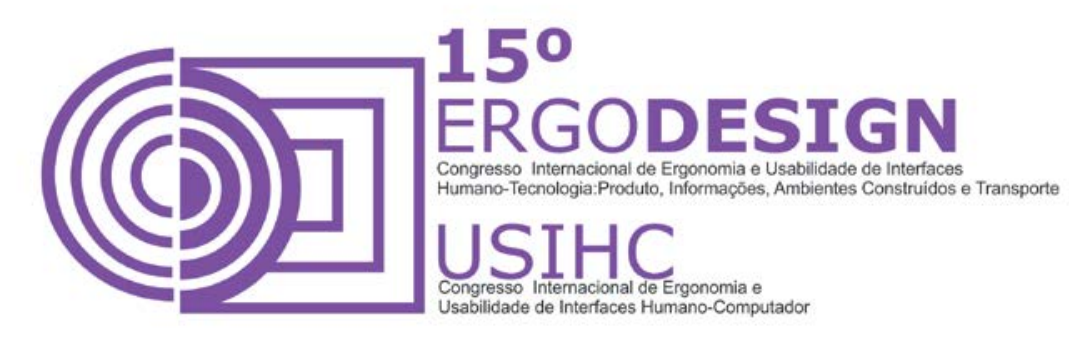

\subsection{O produto extintor de incêndio}

O Extintor de Incêndio é um equipamento portátil ou sobre rodas, indicado para combater princípios de incêndio. Seu conteúdo é composto por um agente extintor e é dotado de um mecanismo para expulsá-lo. Estes agentes identificam a classificação dos extintores que podem ser à base d'água, pó químico e dióxido de carbono $\left(\mathrm{CO}_{2}\right)$.Segundo a ABNT NBR 15808 (BRASIL, 2013), estes diferentes extintores são indicados para uma ou mais classes de incêndio.

O extintor para este estudo especificamente é o portátil com carga de pó químico e para fixação à parede, comumente utilizado em edifícios residenciais. É eficiente para as classes de Incêndio B e C. Basicamente, este tipo de extintor é composto pelos seguintes componentes externos e internos, conforme a Figura 1.

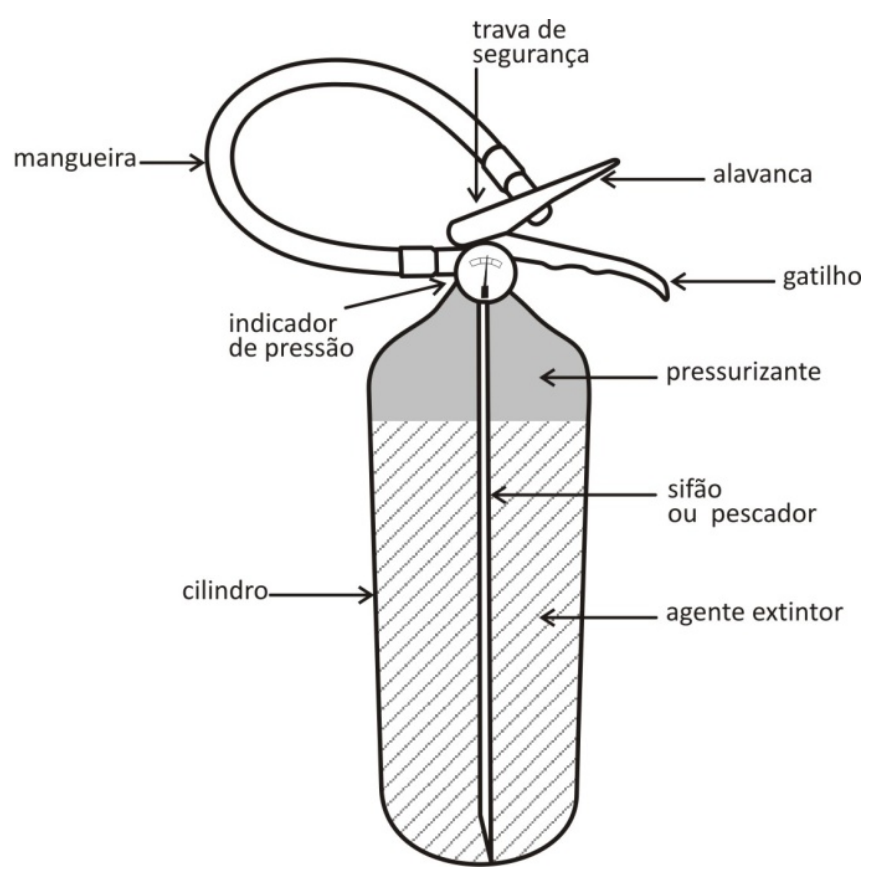

Figura 1. Componentes básicos externos e internos do extintor.

Os extintores devem possuir, também, um Quadro de Instruções de forma legível, contendo informações como: o agente extintor; as classes de fogo a que o equipamento se destina; a faixa de temperatura de operação; grau de capacidade extintora; validade; o logotipo personalizado do fabricante; o lote e o ano de fabricação; entre outras. O Selo do INMETRO (Instituto Nacional de Metrologia, Qualidade e Tecnologia) também é elemento obrigatório que garante a confiabilidade do produto. 


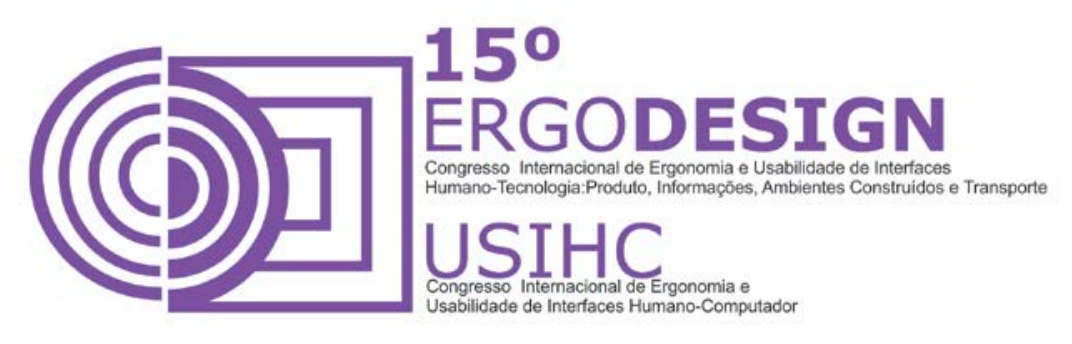

Para a utilização do extintor, basicamente são recomendados os seguintes passos:

1) Segurar o extintor na posição vertical;

2) Romper o lacre;

3) Retirar a trava de segurança;

4) Mirar a mangueira na direção da base do fogo com uma distância idealmente de um metro;

5) Pressionar a alavanca.

É importante que o usuário do extintor se posicione a favor do vento para evitar que a fumaça e o próprio equipamento se torne um empecilho.

Para a manutenção, o extintor deve ser recarregado anualmente ou sempre que, após pesado, houver perda de peso além de 10 (dez) por cento do peso original.

\subsection{UX e affordances físicas}

Affordance é um termo que ganha força devido a estudos na área da psicologia da percepção. Gibson (1979) define affordance como um recurso que o ambiente oferece ao animal (observador), a qual tem a capacidade de perceber e usá-lo..

Além disso, Norman (1988) introduziu o termo affordance para falar sobre o design de objetos de uso diário referindo-se a um atributo de um objeto ao qual permite às pessoas saber como utilizá-los, ou seja, significa "dar uma pista", caso seja perceptível. Desta forma, contribui para a área de projetosde produtos, com os termos affordances "percebidas" e "reais". As affordances percebidas indicam possibilidades de ações que o projetista deseja que o usuário enxergue no produto, de forma que não são necessariamente as mesmas das affordances reais. Já as reais são intrínsecas da natureza física do produto e por isso indicam possibilidades de ações direitas e naturais.

Em paralelo, Pucillo e Cascini (2014) apresentam uma mudança nas últimas décadas em relação ao conceito de usabilidade pela ISO 9241-11 (1996) até a ISO 9241-210 (2010), na qual o termo UX - User Experience (Experiência do Usuário) foi abordado como atitudes, habilidades, hábitos e personalidade do usuário em relação a sua experiência. Discute-se desta forma, a perspectiva ao avaliar a experiência do usuário, não evolvendo apenas a eficiência (erros ao uso), mas também a satisfação (prazer) e a percepção ao experimentar o produto.

Vale destacar queexiste uma complexidade na definição de UX para área do design, no qual os projetos não devem impor comportamento, mas, proporcionar as experiências. Pensando desta maneira, as affordances precisam ser abordadas em projetos de produtos, porém, não apenas com o enfoque nas funções do produto e sim para a percepção dos mesmos. 


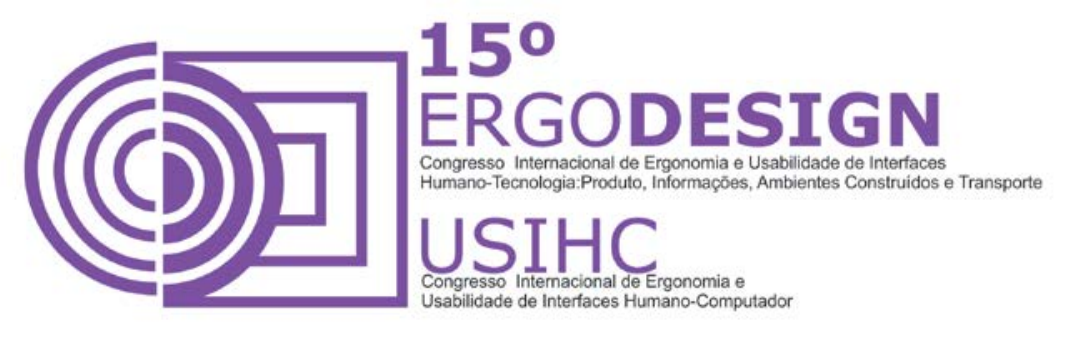

Deste modo, conforme Figura3, as dimensões para usabilidade (percepção, memorização e ação) considerando o desempenho e a impressão do produto, são apresentadas. Nota-se que antes do uso existe a compreensão e o questionamento para o uso. Tal fato varia conforme a situação e complexidade de interação do produto, levando em consideração experiências passadas com informações de uso, proporcionando aprendizado (memorização) e alterando a percepção do usuário. Desta forma, inicia-se o processo de percepção das affordances físicas do produto, que são imutáveis. Todavia, caso seja um primeiro contato com o produto, é possível observar que o uso intuitivo está sendo operado.

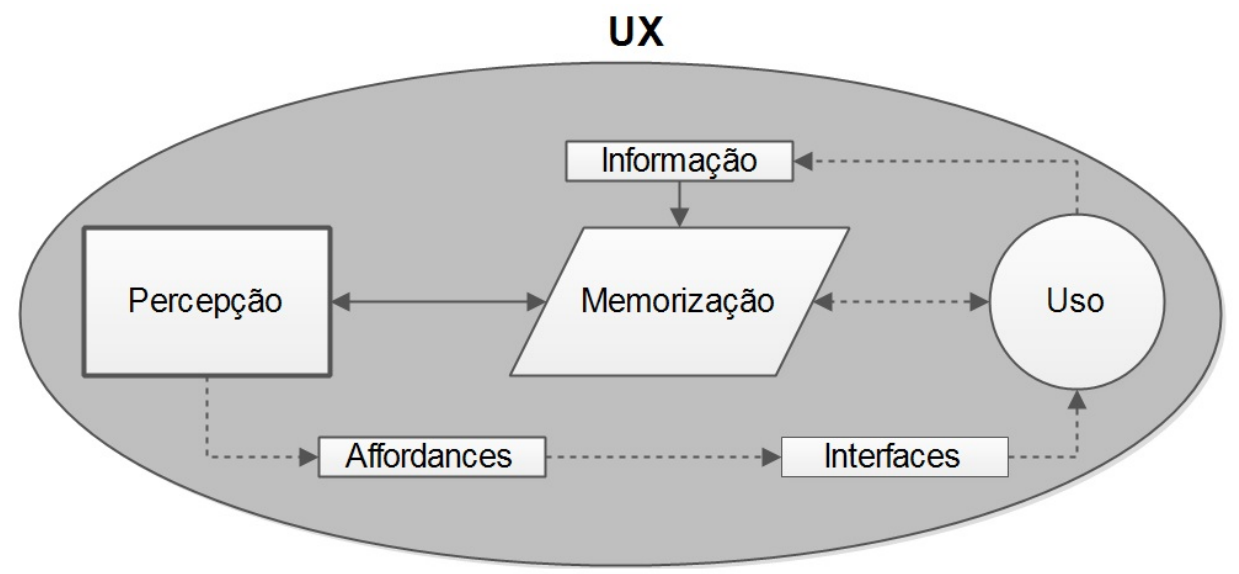

Figura 2. Enfoque na percepção dentro das dimensões de UX. Fonte: Adaptado de Han et al., 2000.

Por fim, o enfoque da pesquisa visa entender a mudança da percepção do usuário perante as affordances, por meio de imagens de um extintor com a tecnologia eye tracking, em um produto que é utilizado em situação de emergência, a qual exige pouco tempo entre a percepção e o uso efetivo.

\section{METODOLOGIA}

A metodologia desta pesquisa está definida como um estudo de caso aplicado segundo Lakatos (2006) centrado numa abordagem mista de caráter exploratório. A avaliação foi realizada no Laboratório de Ergonomia da UFPR (Universidade Federal do Paraná) com 12 usuários queresidem em apartamentos onde possuem extintores, entretanto, nenhum deles poderia terutilizado ou realizado alguma formação prévia. 


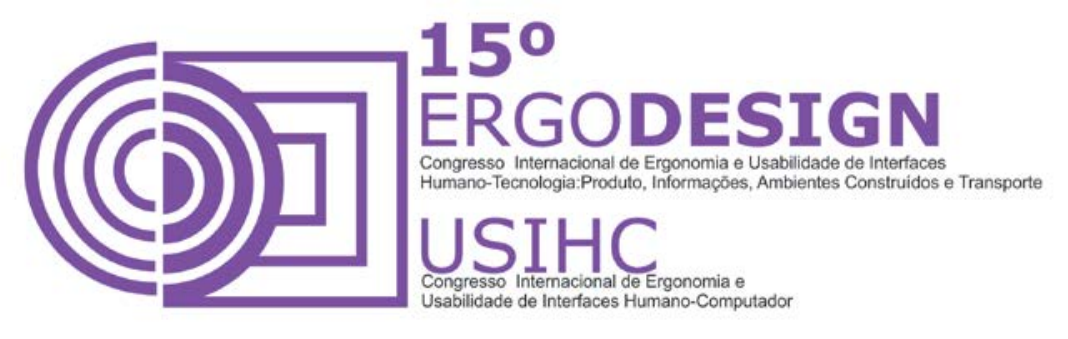

Os equipamentos utilizados para o experimento foram um Eye Tracking de mesa com 60hz e acurácia de 0,5-0.1 graus da marca TheEyeTribe;um laptop de 19 polegadas e um fone de ouvido para áudio simples.

Em relação às etapas, primeiramente os usuários responderam o Termo Livre de Consentimento e esclarecido segundo a norma ERG BR 1002 (2003) e, em seguida, começaram a primeira etapa da avaliação, conforme Figura 3. O teste foi dividido em duas situações: Situação A (1), na qual o usuário observava uma imagem de um extintor suspenso na parede, por exatamente 7 segundos e tinha a sua visualização rastreada. A seguir, o mesmo usuário assistia a um vídeo de cerca de 1 minuto sobre as formas corretas de uso do extintor segundo asinstruções de um bombeiro (2). Depois de recebidas as informações sobre o uso correto do equipamento, o usuário era direcionado para avaliação na Situação B (3), no qual, tinha que observar novamente a mesma imagem na mesma duração de tempo da Situação $A$, com rastreamento ocular.

$\mathrm{Na}$ parte final do processo, os entrevistados responderam a um questionário semiestruturado com informações sobre a mudança de percepção das partes do extintor e também sobre o processo do teste. Os avaliadores anotavam observações como verbalizações ou dificuldades na calibração em ambas as situações:

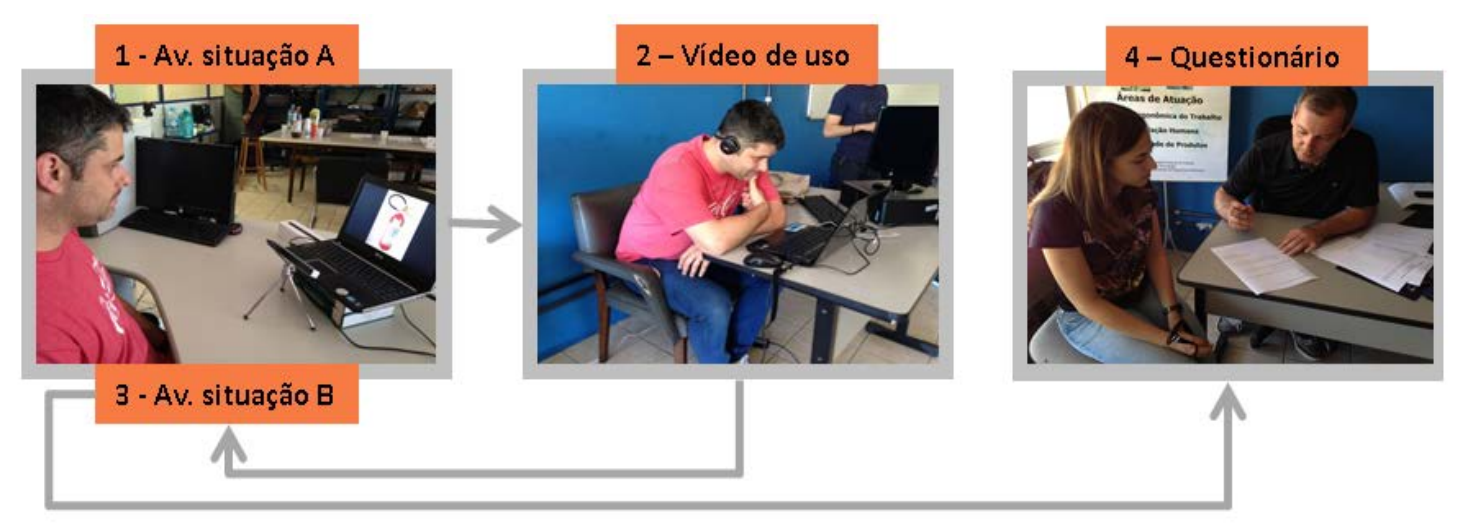

Figura 3. Etapas do processo de avaliação da percepção visual.

\section{RESULTADOS E DISCUSSÃO}

Para uma melhor compreensão dos resultados da pesquisa, foram demarcadas duas áreas de interesse na imagem do extintor de incêndio. A primeira compreendendo a parte superior do equipamento com a inclusão dos seguintes componentes: mangueira, indicador de pressão, trava de segurança, alavanca e gatilho. A segunda área de interesse compreende basicamente o cilindro do extintor, onde constam as instruções de uso do equipamento. Como nomenclatura, a parte superior foi definida como Área 1 e a parte do cilindro como Área 2. Assim, nas 


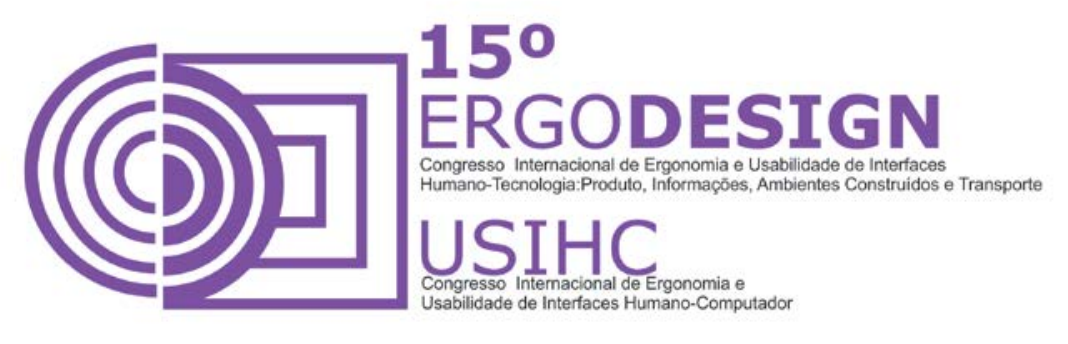

verificações de tempos de fixação as demais áreas foram desconsideradas, onde inclui-se enfoques na parede onde o extintor está afixado.

Como primeira análise buscou-se os heatmaps das visualizações executadas, os quais permitem uma média da visualização dos usuários, bem como pontos de maior tempo de fixação. Assim, conforme Figura 4, os resultados, mostraram que na situação A os usuários agiram de forma mais dispersa, pois tentaram compreender o uso do extintor, dando mais enfoque às instruções impressas no rótulo do cilindro (Área 2). Entretanto, após receberem informações sobre o uso correto, o enfoque na situação B dirigiu-se para parte superior do extintor (Área 1), no qual as funções e dispositivos se sobressaem:

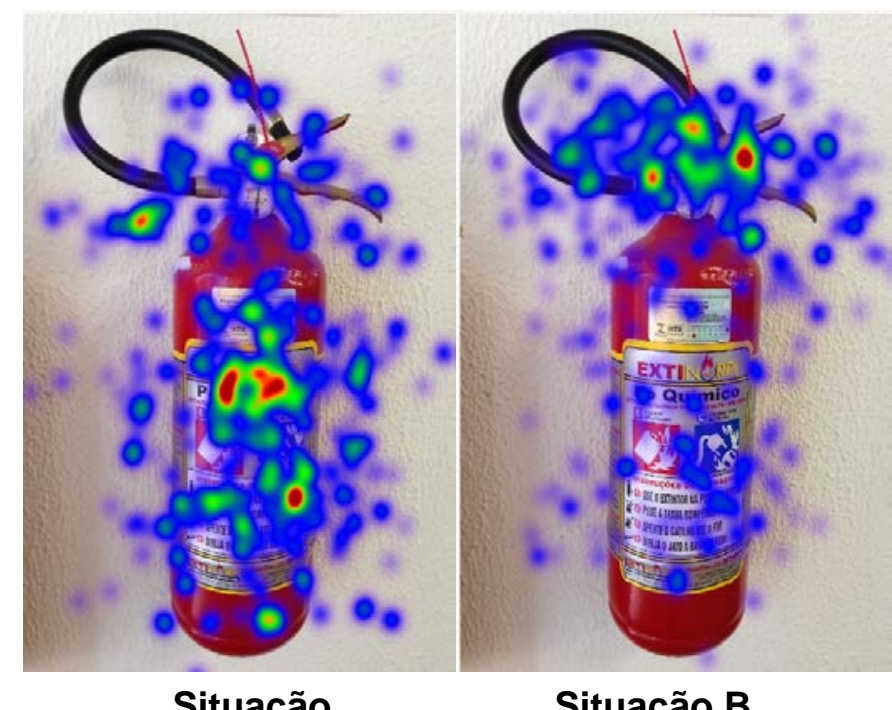

Figura 4. Heatmaps: diferenças entre a situação A e B.

Sendo assim, as affordances físicas reais se tornaram mais perceptíveis após as informações prévias dadas indiretamente pelo vídeo com as instruções de uso do equipamento, tornando-se affordances percebidas pelo usuário. Porém, na situação B ainda existe atenção no cilindro apesar do que menores e sem pontos de fixação intensa.

$\mathrm{Na}$ sequência analisaram-se os tempos de fixação nas duas áreas, com intuito de identificar alterações de visualização. Avaliando-se primeiramente a Situação $A$, assim, o tempo das primeiras fixações concentraram-se na área 1 com 174 milésimos e para área 2, 129 milésimos: 

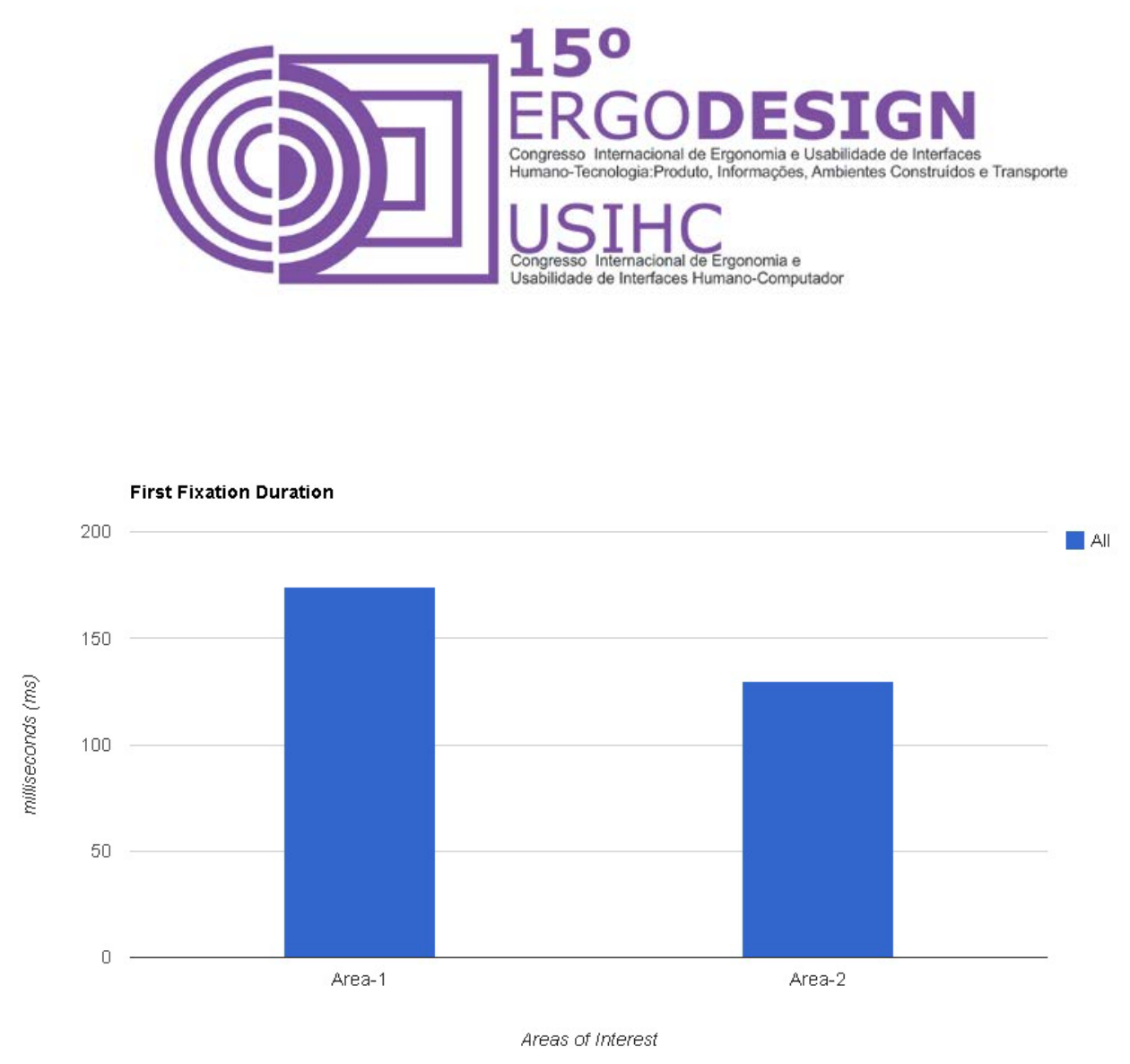

Figura 5 - Tempo médio (primeiras fixações) nas áreas de interesses para a situação A.

Referente ao tempo total de duração, na área 1 foram registrados 840 milésimos e na área 2, 2670 milésimos, como indicado na Figura 6. Isso demostra que os usuários buscaram entender primeiramente as partes e funções do produto e então fixaram na maior parte do tempo na parte central, na qual há as instruções básicas de uso:

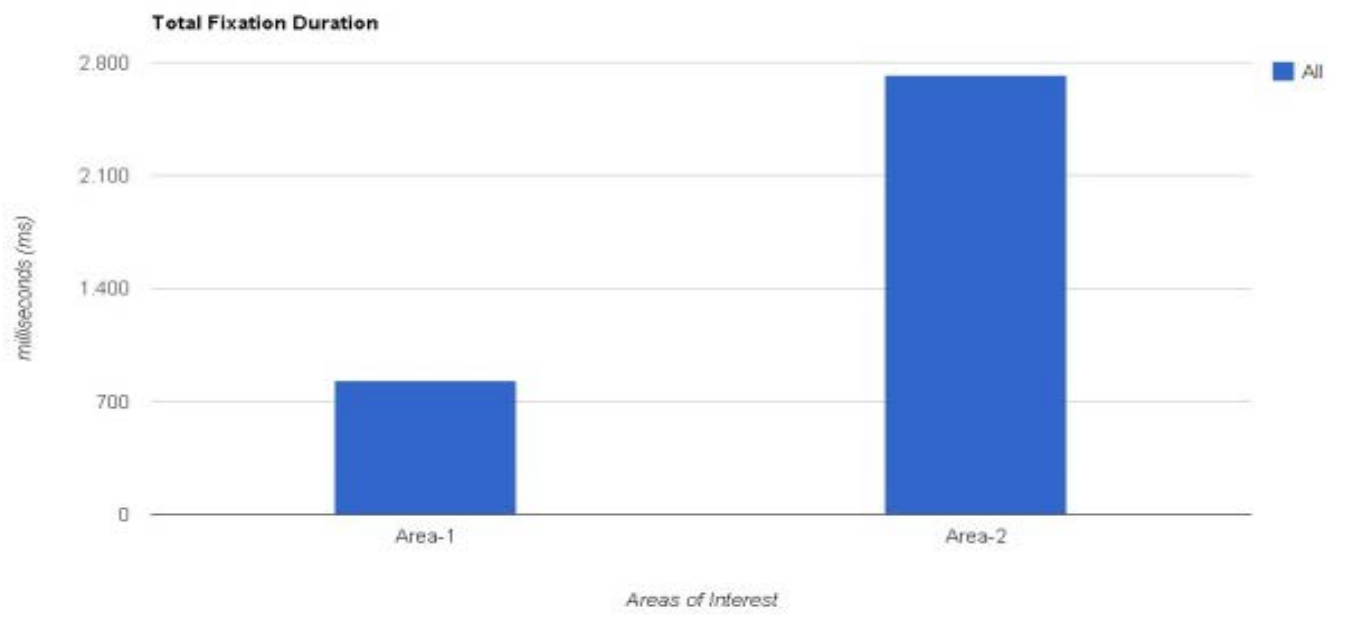

Figura 6. Tempo total de duração nas áreas de interesse para a situação A. 


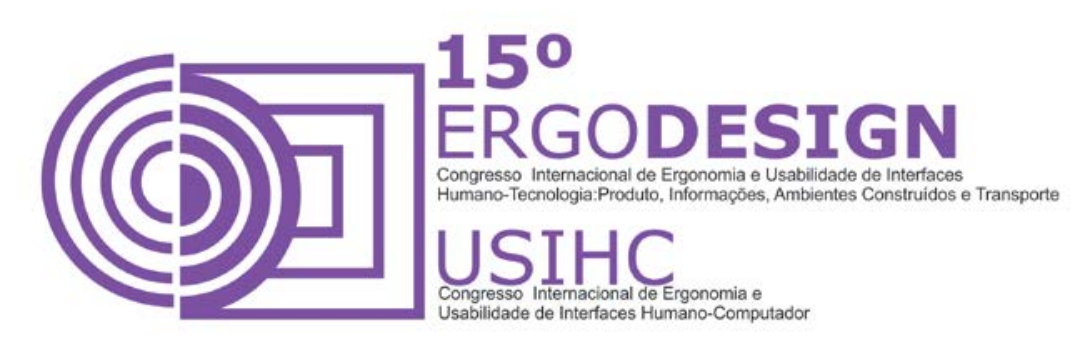

Sobre a situação B para o tempo médio das primeiras fixações, os resultados apresentaram-se parecidos, pois se dirigiu para área 1, totalizando 174 milésimos e para área 2, 126 milésimos:

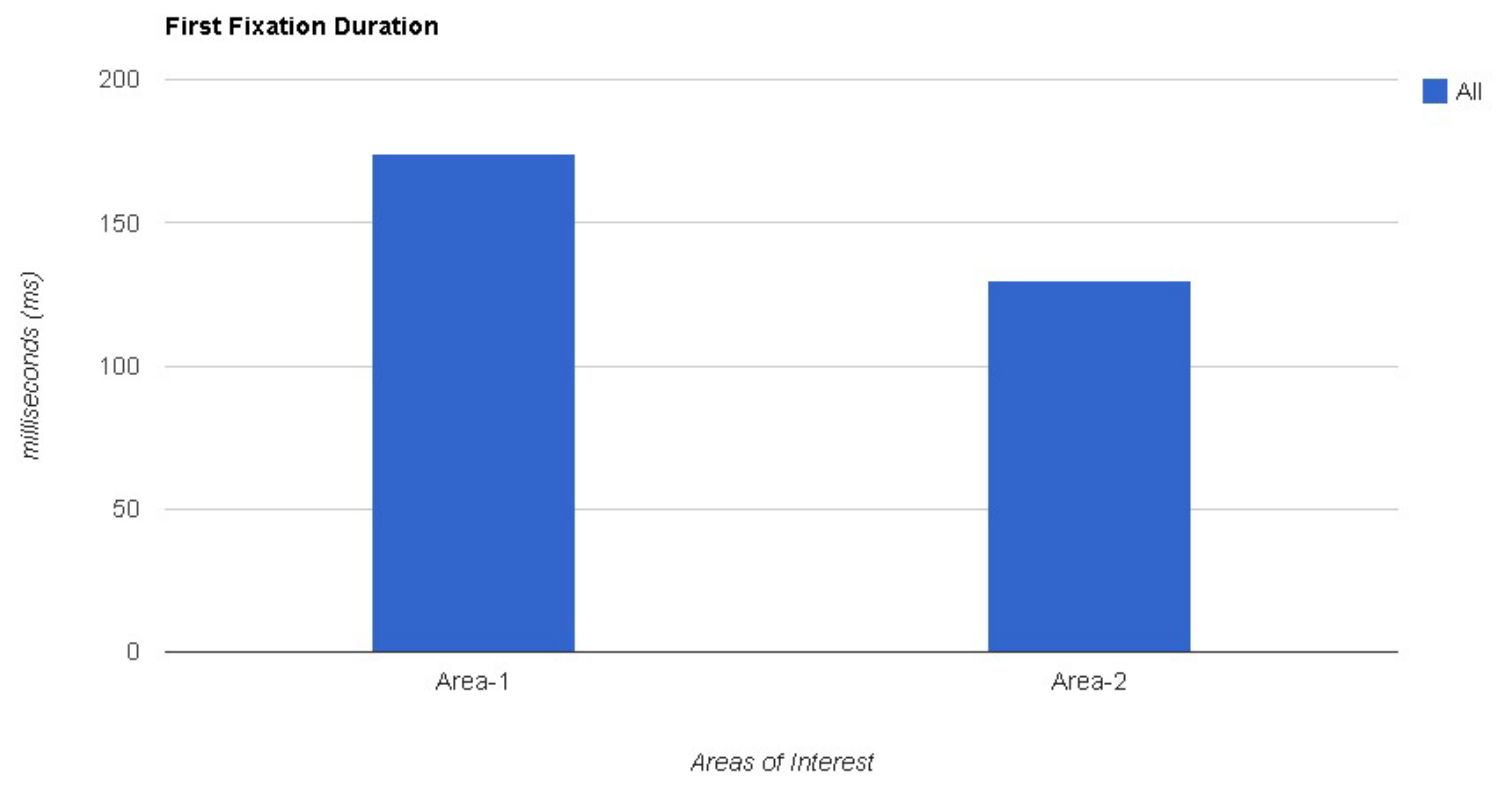

Figura 7. Tempo médio (primeiras fixações) nas áreas de interesses para a situação A.

Entretanto, referente ao tempo total de duração para a situação $B$, os resultado apresentaramse opostos em relação à situação A, pois a área 1 foi registrada com 2089 milésimos e a área 2, 1110 milésimos indicados na Figura 8. Isso demonstra que os usuários primeiramente, buscaram as informações contidas no vídeo (informações prévias), percebendo as affordances físicas no equipamento e continuaram a dar enfoque na área 1 (parte superior), em que as funções e dispositivos são mais complexos, sem a necessidade de atenção intensa à área 2: 

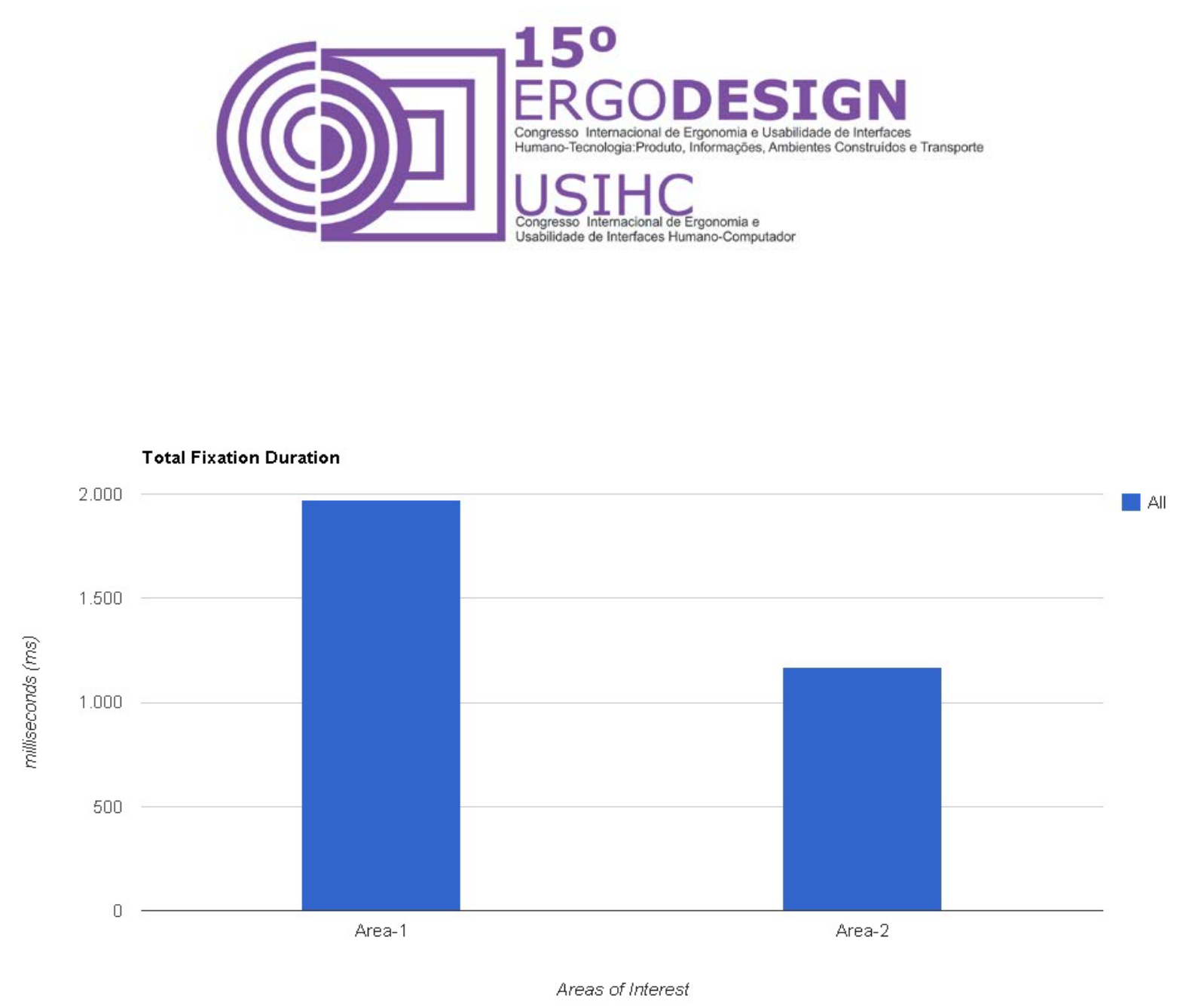

Figura 8. Tempo total de duração nas áreas de interesse para a situação B.

Como etapa complementar de análise, os participantes foram questionados sobre quais partes do extintor de incêndio eles não conheciam e passaram a conhecer a partir do vídeo com as instruções. Os elementos menos conhecidos foram a trava, o lacre de segurança e o indicador de pressão. Depois, solicitou-se aos participantes que citassem características que o extintor deveria possuir para facilitar o entendimento do produto. Ao todo foram listadas 25 respostas, e estas foram divididas em seis categorias, sendo elas:

- Mais simples ou mais intuitivo;

- Rompimento do lacre;

- Instruções de como utilizar o produto;

- Informações sobre a trava de segurança;

- Maneira correta de utilizar a mangueira;

- Outra cor;

As respostas mais citadas estão relacionadas às marcações que deveriam existir no produto, tornando-o mais intuitivo sob o ponto de vista do possível usuário. Foram listadas também características relacionadas a trava contida na parte superior do produto, e em menor proporção foram listadas características relacionadas a cor, situação da mangueira, ou rompimento do lacre. 


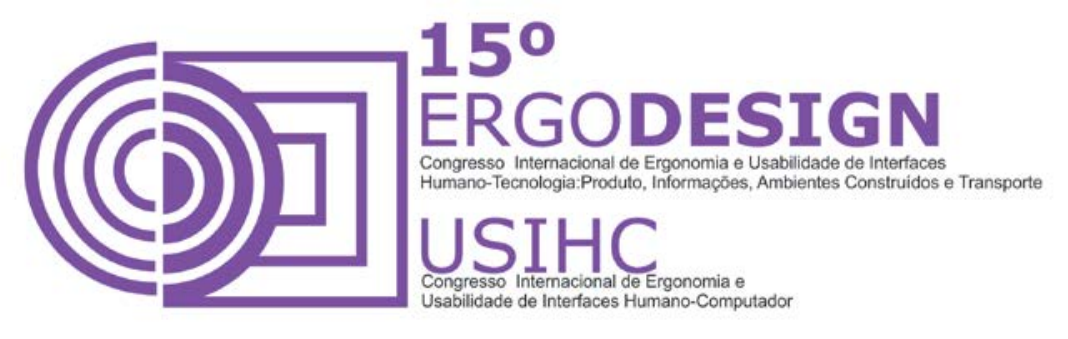

Por fim questionou-se o que os usuários observavam no produto, antes e depois de verem o vídeo. Assim, os participantes indicaram que, em um primeiro momento (situação A), a visualização do produto se dá na forma de um todo para compreender o produto. Já na situação $B$ indicam que tentavam se concentram nos pontos que não conheciam e passaram a conhecer a partir das instruções do vídeo, concentradas basicamente na área 1.

Com a etapa final, verifica-se que existe uma compatibilidade com as informações fornecidas pelos participantes com os resultados analisados a partir do uso do eye tracking. Isso corrobora com a mudança na visualização do produto a partir de um conhecimento prévio, indicando as affordances físicas mais percebidas pelos participantes da pesquisa nos dois momentos.

\section{CONCLUSÃO}

O extintor avaliado nesta pesquisa mostrou-se como de difícil compreensão, pois suas affordances físicas não foram percebidas pelos usuários conforme as tarefas da atividade correta. Sendo assim, o equipamento avaliado carece de interação e intuição. Desta forma, os futuros projetos de extintores de incêndio devem priorizar o uso intuitivo em situações de emergência, em que o usuário não necessite dispensar a maior parte do tempo identificando as instruções de rótulo, e iniciando rapidamentea utilização. Cabe salientar que esta situação deve atender não somente pessoas que possuem formação ou curso, como também possíveis usuários que não estão instruídos, mas tem acesso ao produto.

Para uma análise mais aprofundada, outras questões também devem fazer parte do levantamento das informações como, por exemplo, o meio em que o usuário está inserido, suas referências culturais e sociais, bem como a "sensibilidade ao risco" que segundo Sjöberg (2000) varia muito para cada pessoa.

\section{REFERÊNCIAS BIBLIOGRÁFICAS}

ABERGO. Código de Deontologia do Ergonomista Certificado. Norma ERG BR, 1002, 2003. Disponível em: <http://www.abergo.org.br/arquivos/norma_ergbr_1002/deontologia.pdf.>. Acesso em: Acesso em 05 nov. 2014.

BRASIL. ABNT - Associação Brasileira de Normas Técnicas. NBR 15808: Extintores de incêndio portáteis. Rio de Janeiro: ABNT, 2013. 64p

BRASIL. Governo do Estado do Paraná. Polícia Militar do Paraná. Comando do Corpo de Bombeiros. Código de Segurança Contra Incêndio e Pânico- CSCIP. Curitiba: CBMPR, 2011.

CBMDF - Corpo de Bombeiros Militar do Distrito Federal. Manual Básico de Combate a Incêndio. Brasília-DF: CBMDF, 2009. 


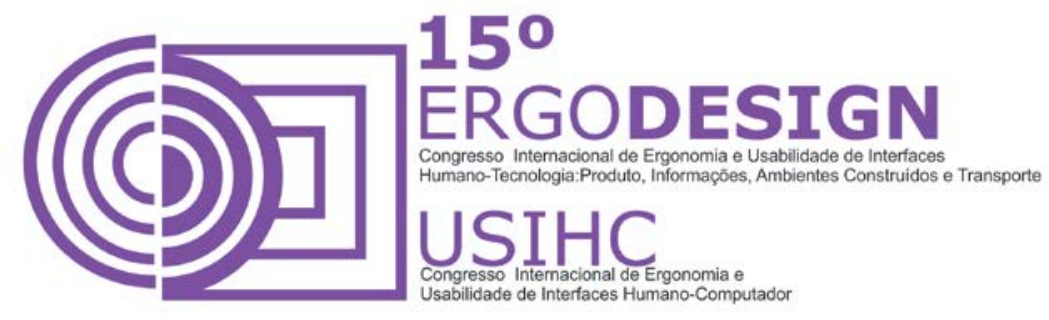

GIBSON, J. J.. The theory of affordances. New York: Lawrence Erlbaum Associates, 1977.

HAN, S. H.; YUN, M. H.; KIM, K.; KWAHK, J. Evaluation of product usability: development and validation of usability dimensions and design elements based on empirical models. In: International Journal of Industrial Ergonomics, vol. 26, 477-488, 2000.

ISO 9241-11. Ergonomic requirements for office work with visual display terminals (VDTs) e Part 11: Guidance on usability. Switzerland: International Organization for Standardization (ISO), 1996.

ISO 9241-210. Ergonomics of human system interaction-Part 210: Human-centred design for interactive systems (formerly known as 13407). Switzerland: International Organization for Standardization (ISO), 2010.

NORMAN, D. A..The psychology of everyday things. New York: Basic Books, 1988.

PUCILLO, Francesco; CASCINI, Gaetano.A framework for user experience, needs and affordances. Design Studies. v, 35, n. 22, 2014.

SJÖBERG, Lennart. Factors in risk perception. Risk Analysis, v. 20, n. 1, p. 1-11, 2000. 